\title{
Simulation of the Effect of Oil Volume Fractions in an Oil-Water Flows Along a Circular Pipe: A Finite Element Approach
}

\author{
Ferdusee Akter ${ }^{1}$, Md. Moniruzzaman Bhuyan ${ }^{2}$, Ujjwal Kumar Deb $^{3}$ \\ ${ }^{1}$ Department of Physical and Mathematical Sciences, Chittagong Veterinary and Animal Sciences University, Bangladesh \\ ${ }^{2}$ Department of Electrical \& Electronic Engineering, Southern University Bangladesh \\ ${ }^{3}$ Department of Mathematics, Chittagong University of Engineering \& Technology, Bangladesh \\ Correspondence: Ferdusee Akter, Department of Physical and Mathematical Sciences, Chittagong Veterinary and Animal \\ Sciences University, Bangladesh. E-mail: ferdusee2008@ gmail.com
}

Received: May 28, 2018 Accepted: June 13, 2018 Online Published: July 9, 2018

doi:10.5539/jmr.v10n5p19 URL: https://doi.org/10.5539/jmr.v10n5p19

\begin{abstract}
Two phase flows in pipelines are very common in industries for the oil transportations. The aim of our work is to observe the effect of oil volume fraction in the oil in water two phase flows. The study has been accomplished using a computational model which is based on a Finite Element Method (FEM) named Galerkin approximation. The velocity profiles and volume fractions are performed by numerical simulations and we have considered the COMSOL Multiphysics Software version 4.2a for our simulation. The computational domain is $8 \mathrm{~m}$ in length and $0.05 \mathrm{~m}$ in radius. The results show that the velocity of the mixture decreases as the oil volume fraction increases. It should be noted that if we gradually increase the volume fractions of oil, the fluid velocity also changes and the saturated level of the volume fraction is $22.3 \%$.
\end{abstract}

Keywords: two phase flow, volume fraction, FEM, CFD simulation

\section{Introduction}

The oil-water two phase flows are very important phenomena for basic research and have many applications in the various field of process industries especially in the petroleum industries. Two phase flow is an extension of single phase flow and more difficult because of the complex behaviour (Drew, 1983). Pipelines are one of the cheapest and efficient way of transportation of fluids. Water is often used for transportation of fluids because it is cheap and relatively safe. Besides, water has a significant effect during the transportation of oil (Alias et al., 2015). The Oiler might be economical to operate with water volume fraction in the liquid phase as high as $90 \%$ (Xu, 2007).

Many extensive researches on oil-water flows in pipes have been performed theoretically and experimentally till today. A method provided by the Electrical Resistance Tomography (ERT) system has been used for measuring the oil in water pipe flow where the volume fraction of oil is upto 23.1\%. It was observed that the ERT method can be used to perform the low fraction oil-water flows. If the oil volume fraction is so high, large oil bubbles or slugs begin to form and also some electrodes lose contact with water (Hua et al., 2005). The velocity profiles and pressure distribution of oil was performed in the presence of gas and it was noted that an increase in the gas volume fraction reduces the pressure drop. However, a discrepant behaviour was found when the gas volume fraction is more than 25\% (Silva \& Marinho, 2014). In 2009, Yaqob and Abbas experimented the performance of a pump by using crude oil-water two phase flow in a centrifugal pump and found that pump head and discharge of two phase flow decreased as oil volume fraction increased. Moreover, the power of the pump increased with the increase of oil volume fraction. A simulation study for viscosity is explained that the viscosity of oil affected the pressure drop and oil volume fraction on a two phase oil-gas flow and found the pressure drop increased as oil viscosity increased. Moreover, Gas phase accumulates at the pipe outlet and decreased the liquid volume fraction along the pipe length (Silva \& Marinho, 2016). From a series experiment of volume fractions shown that the velocity of the oil droplet was power law in shape in a vertical oil-water bubbly flows with the maximum velocity at the center of the pipe and the velocity decreasing to zero at the pipe wall. The oil volume fraction distribution is of power law shape if the mean oil volume fraction is less than $8 \%$, essentially flat for $8 \%$ to $15 \%$ and intermediate peak shape for greater than $15 \%$. The hydrodynamic force is relatively strong for mean oil volume fraction less than $8 \%$ and its direction is in the center of the pipe (Lucas \& Panagiotopoulos, 2009). 
In a study of the effect of velocity using a FEM model, the velocity profile was found a parabolic shape for a channel flow of a two phase flow using Upwind Petrove-Galerkin model (Giordano et al., 2006). A comparison was done between gas-oil and gas-water flow in a vertical pipe. In case of similar velocity, bubbles in air-water flows are larger than in airsilicon oil flow. It is also observe that bubble size distributions are showing local maxima at small bubble sizes (Szalinski et al., 2010). Using volume of fluid method, the authors found the maximum velocity at the center for an annular flow (Desamala, et al., 2014). The axial velocity decreased with an increase in air volume fractions and velocity magnitudes increased with air volume away from the center of the pipe of an air water flow in a pipe separator (Afolabi \& Lee, 2013).

Numerical methods are used to solve problems of Computational Fluid Dynamics (CFD). Numerical techniques gives reliable results which can be achieved more quickly and with lower cost (Silva \& Marinho, 2016; Souza et al., 2011). Among all numerical methods Finite element method gives better approximations to boundary value problems with complex geometries (Yu \& Wiwatanapattaphee, 2006).

In the above studies, we observed some models, experimental and simulated results for two phase flows. These models include the ERT system, Local probe and Petrove Galerkin method etc. Now, in this study we will use FEM based on Galerkin Approximation to investigate the results and predict about the more accurate behabiour of the effect of the volume fractions in case of two phase flow.

\section{Model Formulation}

A mathematical model using Galerkin Finite Element Approximation have used to discuss the two phase flows (Akter \& Deb, 2017). At present, we will see the effect on the velocity distributions in presence of different oil volume fraction in an oil water two phase flows by the model. We considered five cases such as 5\%, 10\%, 15\%, 20\% and $22.3 \%$ oil at the inlet of the computational domain. The initial and boundary conditions for the flow are assumed in a phase field platform.

\subsection{Governing Equations}

In our model we assumed an incompressible and Newtonian flow of two phases consists of oil and water. Besides, the flow is considered as laminar. The Governing equations which represent our model of two phase oil in water flows are given by the following two equations.

$$
\begin{gathered}
\nabla \cdot \vec{u}=0 \\
\rho\left(\frac{\partial \vec{u}}{\partial t}+\vec{u} \cdot \nabla \vec{u}\right)=-\nabla p+\nabla \cdot\left(\mu\left(\nabla \vec{u}+\nabla \vec{u}^{T}\right)\right)+\rho \vec{g}+\vec{F}_{s t} .
\end{gathered}
$$

The following partial differential equation (PDE) is used for the phase field variable, $\varphi$

$$
\frac{\partial \varphi}{\partial t}+\vec{u} \cdot \nabla \varphi=\nabla \cdot \gamma \nabla G
$$

In Phase field method the following equations have used to track the interface between the two phases which is the Cahn-Hilliard equation (Cahn \& Hilliard, 1958).

$$
\begin{gathered}
\frac{\partial \varphi}{\partial t}+\vec{u} \cdot \nabla \varphi=\nabla \cdot \frac{\gamma \lambda}{\varepsilon^{2}} \nabla \psi \\
\psi=-\nabla \cdot \varepsilon^{2} \nabla \varphi+\left(\varphi^{2}-1\right) \varphi+\left(\frac{\varepsilon^{2}}{\lambda}\right) \frac{\partial f}{\partial \varphi},
\end{gathered}
$$


Table 1. Variables and parameters of the model

\begin{tabular}{ll}
\hline Variable/Parameter & Definition \\
\hline$\vec{u}$ & velocity of the mixture \\
$\rho$ & density \\
$\mu$ & viscosity \\
$\vec{g}$ & gravity \\
$\vec{F}_{s t}$ & surface tension force \\
$\mathrm{G}$ & chemical potential \\
$\varphi$ & dimensionless phase field variable \\
$\gamma$ & mobility \\
$\varepsilon$ & controlling interface parameter \\
$\lambda$ & the mixing energy density \\
$\partial f$ & \\
$\partial \varphi$ & $\varphi$ derivative of external free energy \\
$\chi$ & mobility tuning parameter \\
\hline
\end{tabular}

\subsection{Boundary Conditions}

There are three faces present bounding the calculation domain which are inlet boundary, the outlet boundary and the wall boundary. Table 2 represents the boundary conditions for the simulations.

Table 2. Boundary conditions

\begin{tabular}{lc}
\hline Inlet & Velocity, $|\vec{u}|=u_{0}$ \\
\hline Outlet & Zero Normal Stress, \\
& {$\left[-p I+\mu\left(\nabla \vec{u}+\nabla \vec{u}^{T}\right)\right] \cdot \hat{n}=0$} \\
\hline Wall & No-Slip condition, $\vec{u}=0$ \\
\hline
\end{tabular}

\subsection{Galerkin Approximation of the Model}

The Weak formulation of our model for a two phase Newtonian incompressible flow in a computational domain $\Omega$ is by given equation (6) (Akter \& Deb, 2017).

Find $(\vec{u}, p) \in \vec{V} \times Q \quad$ such that for every $t \in I$

$$
\begin{aligned}
& \left(\rho \frac{D \vec{u}}{D t}, \vec{v}\right)-(p, \nabla \cdot \vec{v})+\left(\mu\left(\nabla \vec{u}+\nabla \vec{u}^{T}\right), \nabla \vec{v}\right)-(\rho \vec{g}, \vec{v})-\left(\vec{F}_{s t}, \vec{v}\right)=b(\overrightarrow{\vec{T}}, \vec{v}) \quad \forall \vec{v} \in \vec{V}_{0} \\
& (\nabla \cdot \vec{u}, q)=0, \quad \forall q \in Q \\
& \vec{u}(\vec{x}, 0)=\vec{u}_{0} \text { in } \Omega \\
& \vec{u}=0 \text { on } \Gamma_{u} \\
& \vec{V}=\left\{\vec{v} \mid \vec{v} \in\left[H^{1}(\Omega)\right]^{3}\right\}, \quad V_{0}=\left\{\vec{v} \mid \vec{v} \in \vec{V} \text { and } \vec{v}=0 \text { on } \Gamma_{u}\right\} \\
& Q=\left\{\beta \mid \beta \in H^{1}(\Omega)\right\}
\end{aligned}
$$

Now the Galerkin Approximation of the model (Akter \& Deb, 2017) is shown using equation (7) and (8).

$$
\begin{gathered}
\sum_{l=1}^{N}\left\{\left(\rho \phi_{l}, \phi_{k}\right) \dot{u}_{l}+\left(\rho \phi_{l} \cdot \nabla \phi_{l}, \phi_{k}\right) u_{l}+\left(\mu \nabla \phi_{l}, \nabla \phi_{k}\right) u_{l}+\left(\mu \nabla \phi_{l}^{T}, \nabla \phi_{k}\right) u_{l}^{T}\right\}-\sum_{p=1}^{M}\left(\omega_{p}, \nabla \cdot \phi_{k}\right) p_{p}=\left(\rho \vec{g}, \phi_{k}\right)+\left(\overrightarrow{F_{s t}}, \phi_{k}\right)+b\left(\overrightarrow{\bar{T}}, \phi_{k}\right) \\
\sum_{k=1}^{N}\left(\nabla \cdot \phi_{k}, \omega_{p}\right) u_{k}=0
\end{gathered}
$$




\subsection{Computational Domain and Mesh Generation}

The computational domain is considered as circular tube domain with $8 \mathrm{~m}$ length and $0.05 \mathrm{~m}$ radius. The geometry and a suitable mesh are generated by COMSOL Multiphysics Version 4.2a and properties of the computational domain are shown in Table 3.

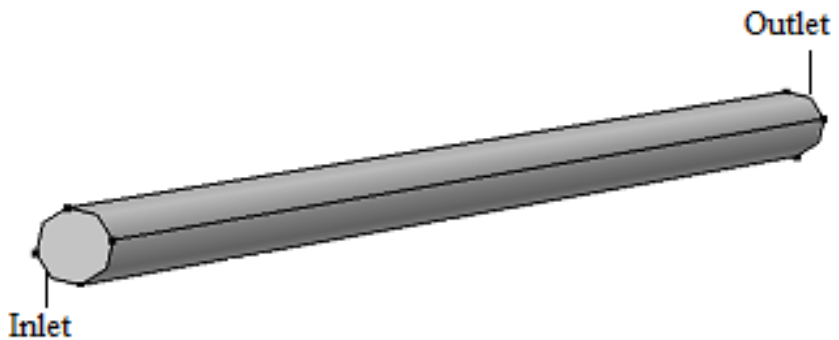

Figure 1. Computational domain

a)

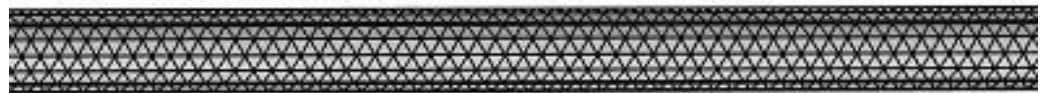

b)

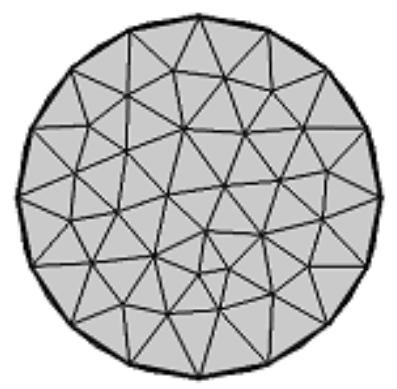

Figure 2. Mesh Design

a) along the pipe b) inlet and outlet of the pipe

Table 3. Properties of the computational domain

\begin{tabular}{lll}
\hline Properties & & Number \\
\hline \multirow{2}{*}{ Elements } & Tetrahedral & 81143 \\
\cline { 2 - 3 } & Boundary & 11374 \\
\cline { 2 - 3 } & Edge & 1432 \\
\cline { 2 - 3 } & Vertex & 8 \\
\hline Degrees of freedom & 619748 \\
\hline Working Volume $\left(\mathrm{m}^{3}\right)$ & 0.0618 \\
\hline Surface Area $\left(\mathrm{m}^{2}\right)$ & 2.518 \\
\hline
\end{tabular}




\section{Numerical Results and Discussion}

To analyze the effect of oil volume fraction on oil in water two phase flows, five cases are assumed upto $22.3 \%$ oil volume fraction. Properties of the fluid phases (Alias et al., 2015) and parameter values used for simulation (Deb et. al 2012, Desamala, et al., 2014) are given in Table 4 and Table 5. The Interfacial tension of oil-water is assumed as $0.17 \mathrm{~N} / \mathrm{m}$ at $20^{\circ} \mathrm{C}$. We have analyzed velocity magnitudes.

Table 4. Properties of the fluids

\begin{tabular}{llr}
\hline Properties & Oil & Water \\
\hline Density $(\rho)$ & $780 \mathrm{~kg} / \mathrm{m}^{3}$ & $998.2 \mathrm{~kg} / \mathrm{m}^{3}$ \\
\hline Dynamic Viscosity $(\mu)$ & 0.00157 Pa.s & 0.001003 Pa.s \\
\hline
\end{tabular}

Table 5. Parameters values for our simulation

\begin{tabular}{cl}
\hline Parameters & \multicolumn{1}{c}{ Values } \\
\hline$u_{0}$ & $0.024 \mathrm{~m} / \mathrm{s}$ \\
$\varepsilon$ & $0.01 \mathrm{~m}$ \\
$\frac{\partial f}{\partial \varphi}$ & $0.01 \mathrm{~J} / \mathrm{m}$ \\
$\chi$ & $1 \mathrm{~m} . \mathrm{s} / \mathrm{kg}$ \\
$\mathrm{g}$ & $9.8 \mathrm{~m} / \mathrm{s}^{2}$ \\
\hline
\end{tabular}




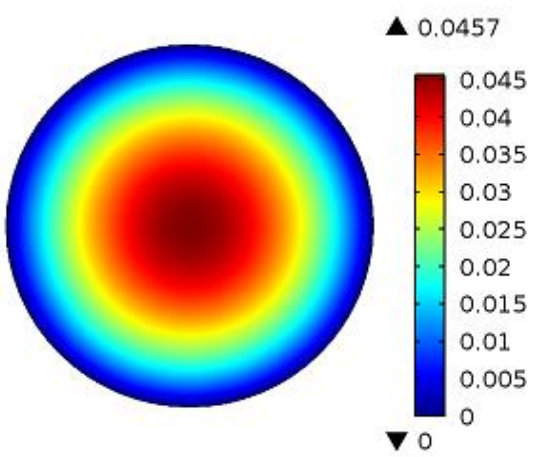

a)

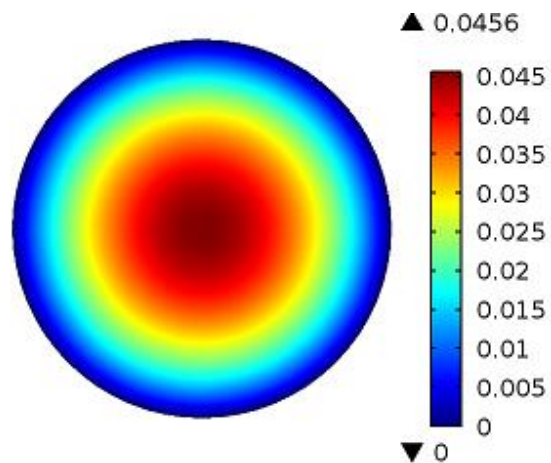

c)

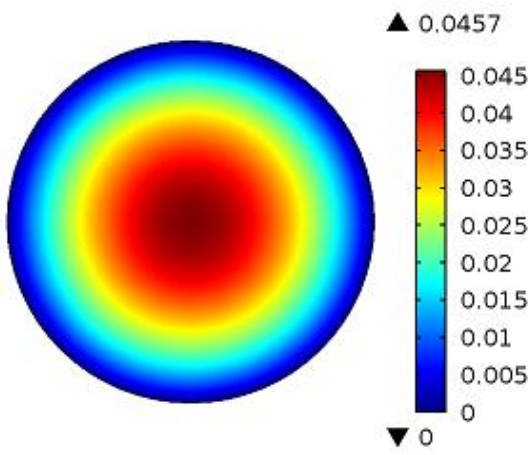

b)

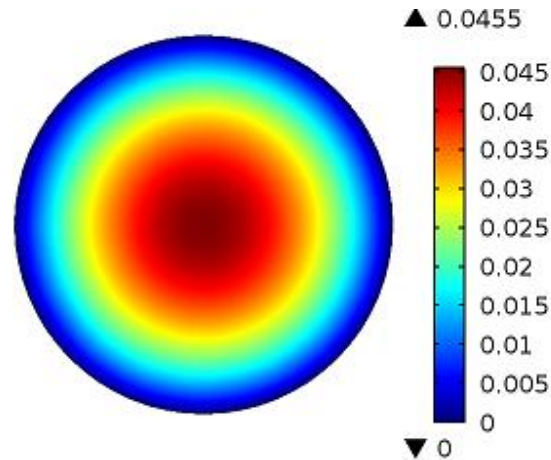

d)

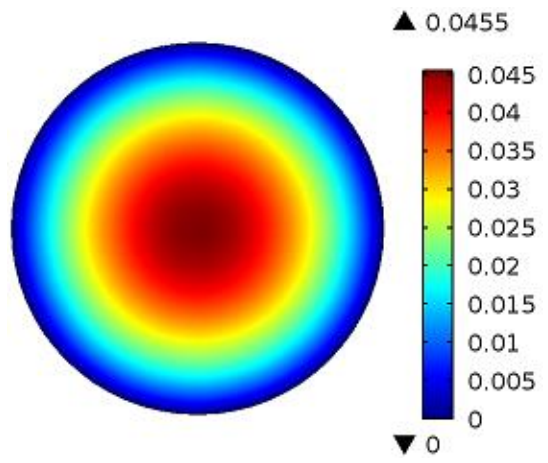

e)

Figure 3. The velocity magnitudes at cross section of $x=8 \mathrm{~m}$ in the computational domain at various volume fractions of oil such as
a) $5 \%$
b) $10 \%$
c) $15 \%$
d) $20 \%$ and e) $22.3 \%$, respectively.

Figure 3 shows the slices of the velocity magnitudes at $x=8 \mathrm{~m}$ of the domain for different volume fractions. We observed the velocity is maximum at the center of the pipe. It is also noted that the velocity of the mixture decreased as the oil volume fraction increased. The reason behind this as we increase the oil volume fractions there may create some large bubbles which resist the flow. Consequently, the velocity is dropping due to oil volume fraction increased. The differences of velocities are low since we used the laminar flow. As the oil volume fraction increased, velocity magnitude decreased and it continues upto a certain level which is $22.3 \%$. However, it is observed that an inconsistent behaviour of the flow while oil is introduced into the pipe greater than $22.3 \%$. Besides, we have got better result for the volume fraction upto $10 \%$. 


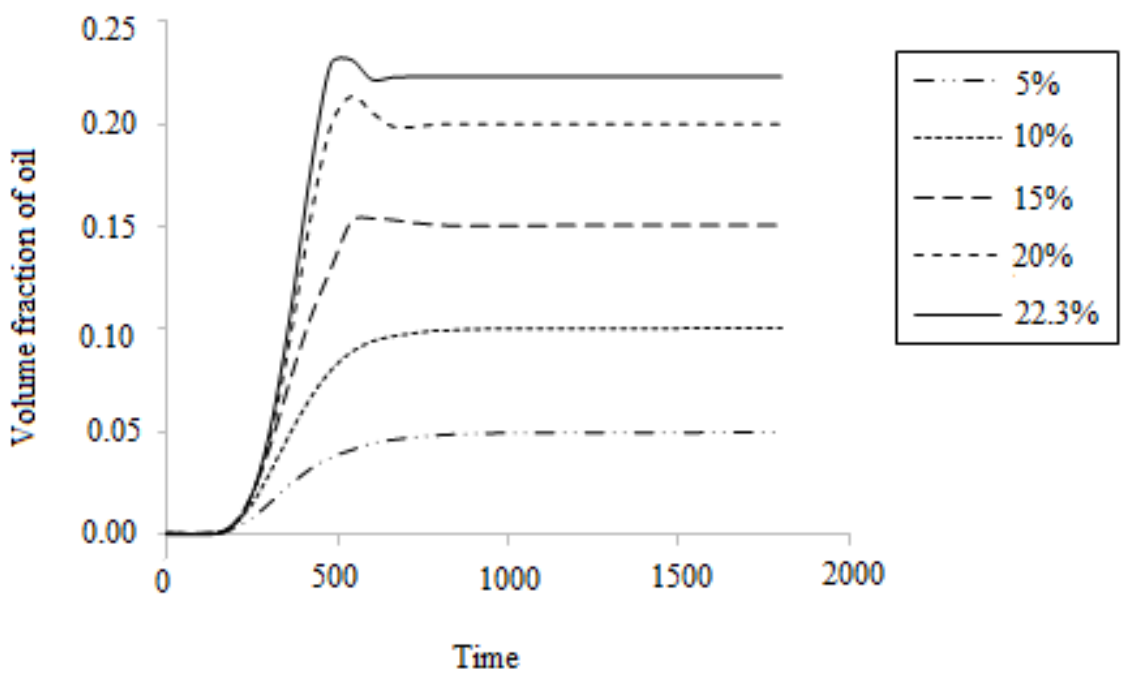

Figure 4. Comparison of volume fraction profiles for different volume fraction of oil in the mixture.

Figure 4 shows a comparison among the oil volume fraction profiles for different ratios of oil-water mixture in the flow. We have increased the volume of oil from $5 \%$ to $25 \%$ with $5 \%$ intervals to check the saturated level. We observed a smooth gradual changes in the volume fractions by following a logistic function upto $10 \%$ of oil volume. In case of the $15 \%$ oil volume fraction in the mixture, a small fluctuation is found. Similar physical behaviour is shown for $20 \%$ also. However, while the volume fraction reached upto $22.3 \%$, a saturated level is observed, after that the simulation does not work. It indicates that the hydrodynamic force is relatively strong for oil volume fraction less or equal to $10 \%$.

By comparing with the study of Hua et al. and Lucas \& Panagiotopoulos our results show an agreement with their results though they have uesd different model for their experiment. On the basis of our results we can suggest that, in practical one can mixed upto $22.3 \%$ oil in water for the saturated level. However upto $10 \%$ oil in water provides better speed in pipe flow.

\section{Conclusion}

The study have done to show the flow characteristics due to different oil volume fractions in an oil-water two phase flows in pipelines. A computational domain is constructed with length $8 \mathrm{~m}$ and radius $0.05 \mathrm{~m}$ respectively to simulate the flow. We considered an incompressible and Newtonian flow of oil-water for our model and the flow is assumed laminar. For the initial condition an inlet velocity of $0.024 \mathrm{~m} / \mathrm{s}$ is taken into account while no-slip condition on the wall and zero normal stress at the outlet is considered. A series of CFD simulations has been completed with the help of COMSOL Multiphysics software version 4.2a which is based on Galerkin Finite Element Approximation. For our simulation we considered different volume fractions of oil including 5\%,10\%, 15\%, 20\% and 25\%. The Numerical results show that an increase in oil volume fraction reduces the velocity of the mixture in the flow. It is also noted that a saturated level of oil can be mixed upto $22.3 \%$. After that an incosistent behaviour was observed. A $10 \%$ mixture of oil give better performance in flow. One can use our concept by putting actual inlet boundary conditions as the physical model support together with a real complex geometries from practical applications.

\section{Acknowledgments}

The authors gratefully acknowledge for the technical support to The Centre of excellence in Mathematics, Department of Mathematics, Mahidol University, Bangkok, Thailand. The authors also acknowledge to the Simulation Lab, Department of Mathematics, Chittagong University of Engineering \& Technology, Bangladesh, for the support to complete this research. 


\section{References}

Afolabi, E. A., \& Lee, J. G. M. (2013). Investigating the Effect of Air Volume Fraction on the Velocity Distributions of Air Water flow in a Pipe Separator. International Journal of Science and Advanced Technology, 3(6), 36- 45.

Akter, F., \& Deb, U. K. (2017). Computational Modeling and Dynamics of the Oil and Water Flow Using the Galerkin Approximation. American Journal of Computational Mathematics, 7, 58-69. https//doi.org/10.4236/ajcm.2017.71005.

Alias, A. Z. M., Koto, J., \& Ahmed, Y. M. (2015). CFD Simulation for Stratified Oil-Water Two-Phase Flow in a Horizontal Pipe. Journal of Subsea and Offshore-Science and Engineering, 2, 1-6.

Cahn J. W., \& Hilliard, J. E., (1958). Free energy of a non-uniform system in Interfacial energy. Journal of Chemical Physics, 28(2), 258-267.

Deb, U. K., Chayantrakom, K., Lenbury, Y., \& Wiwatanapataphee, B. (2012). Numerical simulation of Two-phase laminar Flow for $\mathrm{CO} 2$ and Microalgae Suspension in the HLTP. Latest Advances in System Science and Computational Intelligence, WSEAS Press, Haifa, 53-58.

Desamala, A. B., Dasamahapatra, A. K., \& Mandal, T. K. (2014). Oil -Water Two Phase Flow Characteristics in Horizontal Pipeline A Comprehensive CFD Study. International journal of Chemical, Molecular, Nuclear, Materials and Metallurgical Engineering, World Academy of Science, Engineering and Technology, 8(4), 360-364.

Drew, D. A. (1983). Mathematical modeling of two-phase flow. Annual Reviews on Fluid Mechanics, 15, $261-291$.

Giordano, M., Bonfiglioli, A., \& Magi, V. (2006). A Parallel Finite Element Method for Two Phase Flows. European Conference on Computational Fluid Dynamics, 1-20.

Hua, L., Mi, W., Ying-Xiang, W., Yi-xin, M., \& Richard W. (2005). Measurement of oil volume fraction and velocity distributions in vertical oil in water flows using ERT and a local probe. Journal of Zhejiang University SCIENCE, $6 A$ (12), 1412-1415. https//doi.org/10.1631/jzus.2005.A1412.

Kendoush, A. A., Mahmood, H. B., \& Fiadh, I. G. (2017). Volume Fraction Measurement in Crude Oil -Water Two Phase Mixture using a Neutron Beam. Oriental Journal of Physical Sciences, 02(2), 57-63.

Lucas, G. P., \& Panagiotopoulos, N. (2009). Oil volume fraction and velocity profiles in vertical, bubbly oil in water flows. Flow Measurement and Instrumentation, 20, 127-135. https//doi.org/10.1016/j.flowmeasinst.2009.02.005

Silva, L. D. S., \& Marinho, J. L. G. (2014). Numerical Study on the Influence of Gas Volume Fraction on the Two Phase Flow of Heavy Oil and Natural Gas Mixtures in an Oil Well. Brazilian Journal Of Petroleum And Gas, 8(2), 049-055. https//doi.org/10.5419/bjpg2014-0004.

Silva, L. D. S., \& Mahinho, J. L. G. (2016). Study on Pressure Drop and Liquid Volume Fraction of the Oil-Gas Flow in a Vertical Pipe Using CFX and the Beggs and Brill Correlation: Viscosity Effects. Brazilian Journal Of Petroleum And Gas, 10(1), 001-008. https//doi.org/10.5419/bjpg2016-0001.

Souza, J. S., Farias, F. P. M., Swarnakar, R., Neto, S. R. F., \& Lima, A. G. B. (2011). Non-Isothermal Separation Process of Two-Phase Mixture Water/Ultra-Viscous Heavy Oil by Hydrocyclone. Advances in Chemical Engineering and Science, 1, 271-279. https//doi.org/10.4236/aces.2011.14038.

Szalinski, L., Abdulkareem, L. A., Silva, M. J. D., Thiele, S., Beyer, M., Lucas, D., ... Azzopardi, B. J. (2010). Comparative study of gas-oil and gas-water two-phase flow in a vertical pipe. Chemical Engineering Science, 65, 3836-3848. https//doi.org/10.1016/j.ces.2010.03.024.

Wang, Z., Zhang, Q., Zeng, Q., \& Wei, J. (2016). A Unified Model of Oil/Water Two Phase Flow in the Horizontal Wellbore. SPE Journal, 1-12.

$\mathrm{Xu}$, X. (2007). Study on Oil-Water Two Phase Flow in Horizontal Pipelines. Journal of Petroleum Science and Engineering, 59, 43-58. https//doi.org/10.1016/j.petrol.2007.03.0002.

Yaqob, B. N., \& Abbas, I. F. (2009). Effect of Crude Oil-Water Two Phase Flow on Pump Performance, Eng. \& Tech. Journal, 9, 1766-1774.

Yu, W. H., \& Wiwatanapattaphee, B. (2006). Finite Element Method and Application. Mister-copy Publishing Company, Bangkok. 


\section{Copyrights}

Copyright for this article is retained by the author(s), with first publication rights granted to the journal.

This is an open-access article distributed under the terms and conditions of the Creative Commons Attribution license (http://creativecommons.org/licenses/by/4.0/). 